\title{
Covid and Cardiovascular Diseases: Direct and Indirect Damages and Future Perspective
}

\author{
Giacomo Ruzzenenti ${ }^{1,2} \cdot$ Alessandro Maloberti ${ }^{1,2}$ (D) Valentina Giani $^{1,2} \cdot$ Marco Biolcati $^{1,2} \cdot$ Filippo Leidi $^{1,2}$. \\ Massimiliano Monticelli, ${ }^{1,2}$ Enzo Grasso ${ }^{1,2}$. Iside Cartella ${ }^{1,2}$. Matteo Palazzini ${ }^{1,2}$ - Laura Garatti ${ }^{1,2}$. Nicola Ughi ${ }^{3}$. \\ Claudio Rossetti ${ }^{4}$. Oscar Massimiliano Epis ${ }^{3}$. Cristina Giannattasio ${ }^{1,2}$ on behalf of the Covid-19 Niguarda Working \\ Group
}

Received: 6 April 2021 / Accepted: 27 May 2021 / Published online: 26 June 2021

(C) The Author(s) 2021

\begin{abstract}
SARS-CoV-2 infection determines a disease that predominantly affects lungs. However the cytokines storms, determined by the huge immune response to the infection, could affect also other organs and apparatus such as heart and vessels. Beyond the acute inflammation itself also hypercoagulative status has been linked to SARSCoV-2 infection and this surely relates to the increase seen in prevalence of pulmonary embolism and myocardial infarction. A number of cardiac abnormalities and pathologies have been observed, with special attention to cardiac arrhythmias and myocardial involvement. Furthermore, indirect damages determined by the reduction in acute and chronic cardiovascular care, results in a strong mortality and morbidity outcomes in cardiological patients. In this review we will summarise current knowledge on both direct and indirect cardiovascular damages determined by the SARS-CoV-2 pandemia.
\end{abstract}

Keywords Coronavirus · SARS-CoV-2 · COVID-19 · Cardiovascular · Acute myocardial infarction · Myocarditis

\section{Introduction}

SARS-CoV-2 appeared in the Chinese province of Hubei and rapidly spread around the world. The World Health Organisation qualified it as the sixth public health emergency of international interest. Although this new coronavirus principally determines a respiratory disease (severe Acute Respiratory Distress Syndrome-ARDS), the clinical picture is more complicated and it is characterised by the involvement of many systems at the same time. The large spectrum of organ involvement (e.g., kidney disease,

Alessandro Maloberti

alessandro.maloberti@ospedaleniguarda.it

1 School of Medicine and Surgery, Milano-Bicocca University, Milan, Italy

2 Cardiology 4, Dipartimento A. De Gasperis, ASST GOM Niguarda Hospital, Ospedale Niguarda Ca' Granda, Piazza Ospedale Maggiore 3, 20159 Milan, Italy

3 Division of Rheumatology, Multispecialist Medical Department, ASTT GOM Niguarda Ca' Granda, Milan, Italy

4 Nuclear Medicine, ASST GOM Niguarda Ca' Granda, Milan, Italy thrombosis and pulmonary embolism, cerebrovascular events) during SARS-CoV2 infection is linked to the target damage of the endothelium, one of the largest organs in the human body. SARS-CoV2 accesses host cells using the protein angiotensin-converting enzyme 2 (ACE2), well represented in the endothelium [1].

Among this, also the Cardio-Vascular (CV) system can be severely damaged [2]. It is now clear that both patients with classic CV risk factors (diabetes mellitus, arterial hypertension, obesity) and patients with established CV disease represent a vulnerable population in terms of greater morbidity and mortality [3]. However this topic have been extensively studied and reviewed and its discussion is beyond the purpose of the present paper.

Beside this, SARS-CoV-2 is able to determine CV direct complications such as Acute Coronary Syndrome (ACS), Pulmonary Embolism (PE), myocarditis and the development of arrhythmia. Finally, SARS-CoV-2 pandemic has determined also a reduction in acute and chronic $\mathrm{CV}$ care that has leads to an increase in CV morbidity and mortality (indirect effects). This review will be focused on the direct and indirect $\mathrm{CV}$ effect of SARS-CoV-2 (summarised in Table 1). 
Table 1 SARS-CoV-2 and cardiovascular disease

\begin{tabular}{llll}
\hline COVID-19 and cardiovascular disease & & \\
\hline Direct effects & & Indirect effects \\
\hline Acute myocardial injury & {$[16-25]$} & Discontinuation of cardioprotective drugs & {$[10,11]$} \\
Pericardial and valvular involvement & {$[26-28]$} & Deferring interventional procedures & {$[37-40]$} \\
Arrythmias & {$[29-31]$} & Outpatients visits interruption & {$[41]$} \\
Autonomic dysfunction & {$[32,33]$} & Decrease and delayed hospital presenta- & {$[42-45,53,54]$} \\
Kawasaki-like disease & {$[34]$} & tion for ACS and HF & \\
Takotsubo syndrome & {$[35,36]$} & Increase of complicated ACS & {$[46,47,49-51]$} \\
\hline
\end{tabular}

\section{Direct CV Effects}

CV complication during SARS-CoV-2 infection have been reported since the beginning of the pandemia. Acute myocardial injury, myocarditis, PE, ACS and arrhythmia have been described with a possible role for direct viral contribution. A clear role for a direct viral damage, further reinforced by the cytokines storm in the severe form of the infection, have been clearly depicted for PE and hypercoagulation [4-7]. However, the direct role of the virus in the other CV manifestation have been recently questioned by the results of newer studies. Since the role of SARS-CoV-2 infection in hypercoagulability and PE have been extensively reviewed $[8,9]$ it will not be treated in the present paper that will focus on the other possible $\mathrm{CV}$ direct damages.

First of all, we would like to highlight that the same direct $\mathrm{CV}$ effects could lead to different outcomes according to the patient's comorbidities. Chronic diseases, such as diabetes mellitus, chronic kidney disease, chronic obstructive pulmonary disease and heart failure (HF) could exponentially raise mortality, even after adjustment by age. Charlson comorbidity index score therefore predicts unfavorable outcomes in COVID-19 patients but also identifies people who may benefit from more intense preventive or treatment strategies. In this setting hypertension was not found to be a significant factor influencing clinical outcome [10]. Staying on hypertension issue the issue related to drugs acting on renin angiotensin system (RAS) need to be discussed. In the first phase of the pandemic it was suggested that these drugs might detrimentally influence COVID-19 prognosis by promoting ACE2 expression, the gate SARS-CoV-2 uses to enter and infect the host. This issue received much attention from massmedia and influenced patient behaviour, leading some of them to withdraw these agents (ACE-inhibitors and angiotensin receptor blockers-ARB). Subsequent welldesigned population studies [11], as well as one specific trial [12], clarified that the use of these drugs does not modify susceptibility to COVID-19 neither represent a significant risk factor for death in infected patients. At the opposite, it could be beneficial with respect to in-hospital
CV outcomes in hypertensive patients $[10,11,13]$, probably also due to the fact that their suspension leads to an increase in $\mathrm{CV}$ events.

Among patients with chronic $\mathrm{CV}$ disease more prone to COVID-19 related outcomes, a particular population is the one with congenital heart disease. While pediatric population is relatively spared by SARS-CoV2 infection due to a lesser expression of ACE2, Grown-Up Congenital Heart $(\mathrm{GUCH})$ patients are at greater risk, especially those with residual cardiac problems despite surgical and/or catheter interventions. Patients with unrepaired cyanotic heart disease or severe pulmonary hypertension with Eisenmenger syndrome shows chronic hypoxemia due to a right-to-left shunt and to severe abnormalities of the pulmonary tissue and vascular bed. Severe COVID-19 could exacerbate hypoxemia by increasing right-to-left shunting trough the rise in pulmonary vascular resistance $[14,15]$.

The acute myocardial injury is defined as a sudden raise in the troponin levels over the 99th percentiles and has been associated with higher mortality both in SARS-CoV-2 infection [16-18] and in acute condition other than CoronaVIrusassociated Disease (COVID) [19, 20]. Possible mechanisms underlying myocardial injury in sepsis, and particularly during SARS-CoV-2 infection, has been summarised in Fig. 1.

As already mentioned, mortality is greater in patients who has comorbidities, because these individuals have fewer ability to face a severe illness [21]. At the same time, patients with a stronger inflammatory response, i.e. higher levels of Interleukin-6, C-reactive protein, procalcitonin, ferritin, D-dimer, also presents negative outcomes [16, 17, 22].

Similarly, also the acute myocardial injury during COVID-19 correlate with a worse outcome and higher troponin levels are found in those patients that have demonstrate to be at higher risk, in particular males, older, and with CV comorbidities [16-18, 22, 23].

However, whether the myocardial injury is due to a direct action of the virus over the heart and the vessels or it's a consequence of the severe generalised impairment during viral sepsis, is still matter of debate.

At the beginning of the pandemic, the virus was thought to be able to directly damage the CV system and many cases 


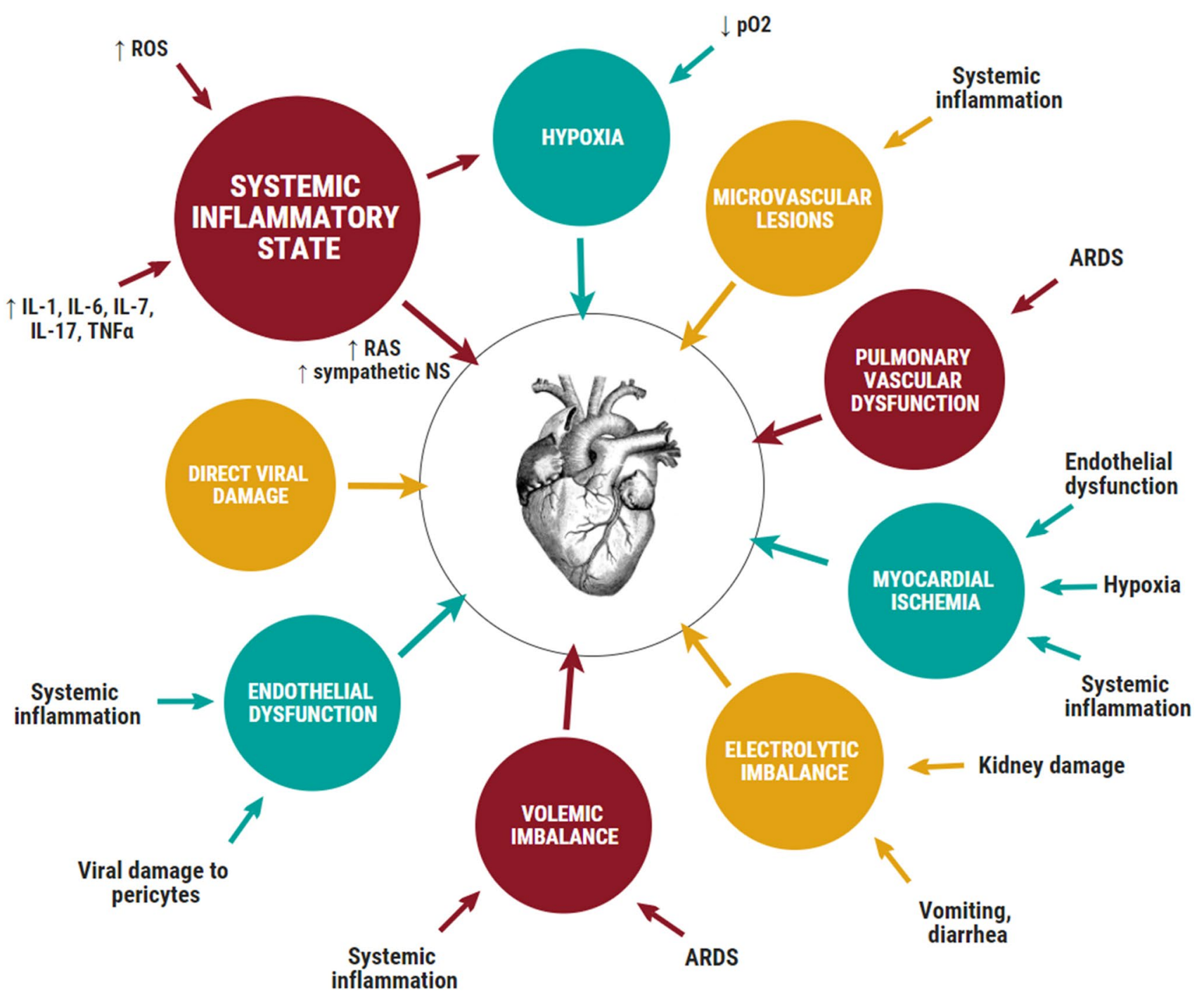

Fig. 1 Possible mechanisms underlying myocardial injury in sepsis, and particularly during SARS-CoV-2 infection

of myocarditis with severe left ventricular impairment were described. However, some new findings questioned this idea. In fact, Basso et al. [24] have analysed the myocardial tissue of 21 patients deceased for COVID-19, the presence of myocarditis, as defined by the presence of multiple foci of inflammation with associated myocyte injury, was determined, and the inflammatory cell composition analysed by immunohistochemistry. The typical histological picture attributable to a myocarditis, with lymphocyte infiltrate, was present only in few cases $(3,14 \%)$. In the majority of patients, the autopsy study reveal a diffuse inflammatory infiltrate formed by monocytes and macrophages without a direct cardiomyocytes injury. This pattern is not a pathognomonic finding for viral myocarditis while it's a frequent finding during cardiac inflammatory involvement due to critical illness. So, it is more probably attributable to inflammatory heart damage during severe sepsis than to direct viral tropism suggesting that myocardial damage may be multifactorial in the course of a critical clinical disease.

So, myocardial injury would seem to be secondary to the multiple events that occur during the massive inflammatory response triggered by the COVID-19 infection, as the cytokine storm [22], the endothelial and microvascular damage [25], the hypercoagulabily state and the increase in metabolic demands in face a reduced supply [16, 24].

In another really interesting study the myocardial involvement observed during COVID-19 infection was compared to that observed during critical bacterial pneumonias. Myocardial damage prevalence is less frequent in SARS-CoV2 pneumonias than in pneumonia of other aetiology (78.1 vs $96.4 \%, p=0.004)$ with similar rate of left ventricular systolic dysfunction and in-hospital mortality (38.2 vs. 51.3\%, $\mathrm{p}=0.142$ ). Also these results reinforce the hypothesis that myocardial damage during SARS-CoV-2 infection is not a 
pathognomonic event triggered directly by the virus per se, but it depends on the severe systemic inflammatory state and the severity of the clinical condition [23].

Furthermore, other cardiac structure besides cardiomyocytes, could be involved by the infection. In fact, cardiopulmonary serosal layers involvement has been reported ranging from asymptomatic pericardial involvement to clinical pericarditis and pericardial effusion till life threatening cardiac tamponade [26]. Similarly to myocardial damage, even if a study demonstrated the presence of COVID-19 in the pericardial fluid [27], it remains unclear whether pericarditis represents a primary viral involvement or it is part of a more generalized multisystemic inflammatory syndrome. With regards to treatment, high dose NSAIDs, colchicine and glucocorticoids could be used for acute pericarditis, even in the setting of SARS-CoV2 infection.

Valvular apparatus could also be involved and Khanduri et al described a case of mitral valve regurgitation complicated by pulmonary oedema and respiratory failure secondary to direct valvular damage from COVID-19 infection [28]. The evaluation of the valve shown myxomatous degeneration with an inflammatory infiltrate of $\mathrm{T}$ lymphocytes and histiocytes. ACE2 receptors has been detected in endomyocardial tissue, especially on cardiac valves, giving us a possible explanation to primary valvular damage.

The arrhythmic risk related to COVID is still under evaluation [29, 30]. The most common arrhythmia related to SARS-Cov-2 infection is sinus tachycardia, with palpitations as the principal clinical presentation [31]. However, also other arrhythmia such as high grade atrioventricular block, atrial fibrillation, polymorphic ventricular tachycardia and pulseless electrical activity cardiac arrest has been described, highlightening the importance of appropriate rhythm monitoring in these patients. Some of this complication are surely related to proinflammatory state, cytokine storm and electrolytic abnormalities, such as atrial fibrillation, or hypercoagulative state (pulseless electrical activity related to PE) while a direct role for virus per se has never been demonstrated. Furthermore, also QT-prolonging due to side effects of drugs commonly used during the first pandemic wave, such as azithromycin and hydroxychloroquine, has been described.

Another possible direct damage of the virus could be at the level of the autonomic system leading to what has been called long-COVID. It is defined as the permanence of symptoms beyond the acute phase of the disease for a period of about 3 weeks, instead, the prolongation of symptoms for over 12 weeks is called chronic-COVID. Patients more frequently complain dyspnoea, palpitations, asthenia, fatigue and orthostatic hypotension. Although, the long-term effects of COVID-19 infection are still unknown and very few studies have been published, it has been hypothesized that some of these symptoms (at least orthostatic hypotension and tachycardia) may result from a dysfunction of the autonomic nervous system. Autonomic dysfunction could result from direct viral damage to the autonomic nervous system or secondary to an autoimmune mechanism [32, 33]. However, more studies are necessary to better understand this issue.

Despite being less affected, children are not totally spared by COVID-19. In fact, Verdoni et al described ten cases of a Kawasaki-like disease occurring in Bergamo (Italy), as a consequence of SARS-CoV2 infection with a monthly incidence 30-fold higher. Clinical features were similar to that of classical Kawasaki disease but patients were older and had a higher rate of cardiac involvement and macrophage activation syndrome, often requiring high dose corticosteroids in addition to intravenous immunoglobulin [34].

The last consequence of SARS-CoV2 pandemic may be considered both a direct and an indirect effect. During the pandemic several studies reported an increased incidence of takotsubo syndrome, both in the general population and in infected patients. According to Jabri et al. [35], during pandemic $7.75 \%$ of patients presenting with acute coronary syndrome revealed to be stress-induced cardiomyopathy, opposite to only $1,5 \%$ before the pandemic.

Mechanisms are mainly linked to the cytokine storm, the increased sympathetic responses and the microvascular dysfunction in infected patients, while psychosocial distress (due to social distancing, economic concerns, fear of contracting the virus) plays a central role in the general population [36].

\section{Indirect CV Damages}

The COVID-19 pandemic had strong implications on $\mathrm{CV}$ diseases also without the direct involvement of the SARS-CoV-2.

Throughout the medical emergency, many hospitals were forced to reset their organisation by moving bedsides and employees in order to receive SARS-CoV-2 infection cases. That caused several difficulties in hospital routine activities, including cardiology services. According to the ESC guidelines for the diagnosis and management of cardiovascular disease during the pandemic [37], non-urgent procedures were suspended; at least $95 \%$ of the elective coronarographies in patients with a positive stress test were reduced or completely stopped. Obviously, also other interventional procedures such as valve implantation at the aortic or mitralic levels incurred in a considerable decrease [38]. As a consequence, a higher mortality has been reported and it could be possible that a subsequent increase in chronic complications (principally HF due to left ventricular dysfunction) will emerged in the near future $[39,40]$. Similarly, outpatient visits were interrupted for a long time, especially at the beginning of the pandemic, and despite the great impetus given to telemedicine systems 
[41] (i.e. telephone and video-assisted consultations), followup of many cardiologic patients was discontinued.

In addition, lifestyle changes have been made mandatory by governments in order to reduce the spread of the infection, including limitations of contacts through social distancing, restrictions to many activities and in extreme cases through a complete lockdown. In the same period, there was a drastic reduction in the number of patients referring to hospital for non-COVID-19 symptoms due to the fear of being infected in the emergency department or during hospitalization [42, 43]. Regarding cardiological condition, data collected by a multicentric observational study on March 2020 revealed a $48.4 \%$ reduction of the admissions to hospital for ACS compared with the equivalent days in 2019 [44]. These results were almost similar in other countries as evidence of a general trend towards avoiding emergency departments because considered as major outbreaks of infection [45]. At the same time, a 58\% increase on out-of-hospital cardiac arrest was reported in Lombardy during the first 40 days of the COVID-19 outbreak in comparison to the same period of the year before [46]. Although the real prevalence of out-of-hospital cardiac arrest in the setting of an ACS is unknown, it is estimated that up to $75 \%$ of mortality occurs before medical contact [47]. Whether it remains to be ascertained, it is likelihood to assume the existence of a link between reluctance to access medical assistance and the increase in out-of-hospital cardiac arrest.

At the same time, also the amount of late-presenter ACS raised during the pandemic outbreak. Data collected from Hong Kong showed an extension in median time from symptoms onset to first medical contact from 82.5 to $318 \mathrm{~min}$, and an increase in median door-to-balloon time from 84.5 to $110 \mathrm{~min}$ [48]. Another German study revealed a $21 \%$ increase in delayed presentation (defined as $>72 \mathrm{~h}$ from symptoms onset) in ACS patients compared to the pre-SARS-CoV-2 pandemic [49]. As well known, ischemia duration is one of the major determinant of subsequent complication in ACS and is directly related to short- and long-term survival [50]. Beside this, also lack of or delayed access to reperfusion treatment lead to an increase in short-term ACS complications. In fact, many studies [49, 51] described a significant growth in mechanical complications, left ventricular systolic dysfunction, intraventricular thrombus and a higher rate of subsequent $\mathrm{CV}$ events (cardiac arrest, cardiogenic shock, and life-threatening arrhythmias).

Similar data were also reported regarding arrhythmias. In the nationwide Danish registries, during the first 3 weeks of COVID-19 lockdown, the incidence of new-onset atrial fibrillation (AF) was lower (-47\%) compared with the corresponding weeks in 2019 [52]. Patients diagnosed with AF during the lockdown were younger and had a higher prevalence of cancer history, HF, and vascular disease as compared with those diagnosed in the previous year. This result is probably determined by the fact that those patients are subjected to a stronger surveillance and so an increasing chances of undergoing physical exam or ECG and discover AF. Similarly to what happen to ischaemic cardiac disease, also ischaemic stroke and all-cause death related to registered new-onset $\mathrm{AF}$ seemed to increase following lockdown, though no statistically significant difference was reached [52].

The same was also observed for HF hospitalization. In the period between March and April a 29\% decline was observed in HF hospitalizations in comparison with the same period of 2019 [53]. Also an increase in mortality of patients hospitalized for HF was observed probably determined by a delay in presentation with worst clinical condition at admission. Again, this phenomenon could also be explained by the fact that a lot of patients, scared by the risk of contagion during hospitalization, avoided to go to the hospital despite symptoms or access emergency department with delay [54].

\section{Perspective}

The year after the outbreak of SARS-CoV-2, with the subsequent unprecedented health emergency, was a very hard time for health systems, health workers and patients too. The difficulties faced must be turned into positive lessons and perspective for the future for all the health system and for CV disease too.

SARS-CoV2 pandemic has upset healthcare systems all around the world, highlighting many challenges that we have been dealing with. An example could be the prevention (in general and in the CV field) that was too often forgotten and affected by economic cuts despite being a cornerstone in achieving a healthy population. Greater investments in primary prevention could reduce the number of "vulnerable" patients, often frail elderly with multiple chronic diseases, and reduce the slice of population at greater risk of mortality in an emerging pandemic disease like COVID-19. In addition to primary prevention, aimed at preventing the onset of disease, the SARS-CoV2 pandemic has also further required the need of investing in secondary prevention, aimed at protecting patients that already experienced a CV event. In this sense, the empowerment of the out-of-hospital network of general practitioners, nurses, health assistants and pharmacies would allow not only a better management of secondary prevention and frailty, but also a greater attention to the prevention of chronic diseases and a lower need for access to the hospital.

The importance of telemedicine was then rediscovered as a fundamental tool during the pandemic to maintain a "safe distance" without giving up visits and health checks. Information technologies are getting more and more refined and could represent in the future an essential tool for remote management of therapy, compilation of therapeutic plans and transmission of vital parameters directly collected by the patient himself. 
Furthermore, a correct communication of information played a fundamental role during the pandemic. The mass spreading of informations, through television, newspapers and, particularly, social media have become a tool for health education and they should be used in the future to increase adherence to vaccinations and mass screening but also to primary and secondary prevention of $\mathrm{CV}$ diseases.

The last lesson that COVID-19 could leave us is about vaccinations. Vaccinations against SARS-CoV2 represent in this moment the only way to overcome the actual pandemic. Our hope is that this disease leaves in the population a greater trust in vaccinations, a fundamental strategy of primary prevention, also in $\mathrm{CV}$ patients.

Funding Open access funding provided by Università degli Studi di Milano - Bicocca within the CRUI-CARE Agreement. This work was funded by the: Italian Ministry of University and Research (MIUR)Department of Excellence project PREMIA (PREcision MedIcine Approach: bringing biomarker research to clinic). A. De Gasperis Cardiology and Cardiac Surgery Foundation.

\section{Declarations}

Conflict of interest All the authors declares that they have no conflict of interest.

Open Access This article is licensed under a Creative Commons Attribution-NonCommercial 4.0 International License, which permits any non-commercial use, sharing, adaptation, distribution and reproduction in any medium or format, as long as you give appropriate credit to the original author(s) and the source, provide a link to the Creative Commons licence, and indicate if changes were made. The images or other third party material in this article are included in the article's Creative Commons licence, unless indicated otherwise in a credit line to the material. If material is not included in the article's Creative Commons licence and your intended use is not permitted by statutory regulation or exceeds the permitted use, you will need to obtain permission directly from the copyright holder. To view a copy of this licence, visit http://creativecommons.org/licenses/by-nc/4.0/.

\section{References}

1. Sardu C, Gambardella J, Morelli MB, Wang X, Marfella R, Santulli G. Hypertension, thrombosis, kidney failure, and diabetes: is COVID-19 an endothelial disease? A comprehensive evaluation of clinical and basic evidence. J Clin Med. 2020;9(5):1417.

2. Kifer D, Bugada D, Villar-Garcia J, Gudelj I, Menni C, Sudre C, Vučković F, Ugrina I, Lorini LF, Posso M, Bettinelli S, Ughi N, Maloberti A, Epis O, Giannattasio C, et al. Effects of environmental factors on severity and mortality of COVID-19. Front Med (Lausanne). 2021;7:607786.

3. Mancusi C, Grassi G, Borghi C, Ferri C, Muiesan ML, Volpe M, Iaccarino G, SARS-RAS Investigator Group. Clinical characteristics and outcomes of patients with COVID-19 infection: the results of the SARS-RAS Study of the Italian Society of Hypertension. High Blood Press Cardiovasc Prev. 2021;28(1):5-11.

4. Danzi GB, Loffi M, Galeazzi G, Gherbesi E. Acute pulmonary embolism and COVID-19 pneumonia: a random association? Eur Heart J. 2020;41(19):1858.
5. Poissy J, Goutay J, Caplan M, Parmentier E, Duburcq T, Lassalle F, Jeanpierre E, Rauch A, Labreuche J, Susen S, Lille ICU Haemostasis COVID-19 Group. Pulmonary embolism in patients with COVID-19: awareness of an increased prevalence. Circulation. 2020;142(2):184-6.

6. Poyiadji N, Cormier P, Patel PY, Hadied MO, Bhargava P, Khanna K, Nadig J, Keimig T, Spizarny D, Reeser N, Klochko C, Peterson EL, Song T. Acute pulmonary embolism and COVID-19. Radiology. 2020;297(3):E335-8.

7. Rico-Mesa JS, Rosas D, Ahmadian-Tehrani A, White A, Anderson AS, Chilton R. The role of anticoagulation in COVID-19-induced hypercoagulability. Curr Cardiol Rep. 2020;22(7):53.

8. Roncon L, Zuin M, Barco S, Valerio L, Zuliani G, Zonzin P, Konstantinides SV. Incidence of acute pulmonary embolism in COVID-19 patients: Systematic review and meta-analysis. Eur J Intern Med. 2020;82:29-37.

9. Suh YJ, Hong H, Ohana M, Bompard F, Revel MP, Valle C, Gervaise A, Poissy J, Susen S, Hékimian G, Artifoni M, Periard D, Contou D, Delaloye J, Sanchez B, Fang C, Garzillo G, Robbie $\mathrm{H}$, Yoon SH. Pulmonary embolism and deep vein thrombosis in COVID-19: a systematic review and meta-analysis. Radiology. 2021;298(2):E70-80

10. Iaccarino G, Grassi G, Borghi C, Ferri C, Salvetti M, Volpe $\mathrm{M}$, SARS-RAS Investigators. Age and multimorbidity predict death among COVID-19 patients: results of the SARS-RAS Study of the Italian Society of Hypertension. Hypertension. 2020;76(2):366-72.

11. Mancia G, Rea F, Ludergnani M, Apolone G, Corrao G. Reninangiotensin-aldosterone system blockers and the risk of covid-19. N Engl J Med. 2020;382(25):2431-40.

12. Lopes RD, Macedo AVS, de Barros-e-Silva PGM, Moll-Bernardes RJ, Feldman A, Arruda GDAS, de Souza AS, de Albuquerque DC, Mazza L, Santos MF, Salvador NZ, Gibson CM, Granger CB, Alexander JH, de Souza OF, BRACE CORONA Investigators. Continuing versus suspending angiotensin-converting enzyme inhibitors and angiotensin receptor blockers: impact on adverse outcomes in hospitalized patients with severe acute respiratory syndrome coronavirus 2 (SARS-CoV-2) - the BRACE CORONA Trial. Am Heart J. 2020;226:49-59.

13. Negreira-Caamaño M, Piqueras-Flores J, Martínez-DelRio J, Nieto-Sandoval-Martin-DeLaSierra P, Aguila-Gordo D, MateoGomez C, Salas-Bravo D, Rodriguez-Martinez M, NegreiraCaamaño M. Impact of treatment with renin-angiotensin system inhibitors on clinical outcomes in hypertensive patients hospitalized with COVID-19. High Blood Press Cardiovasc Prev. 2020;27(6):561-68.

14. Giordano R, Cantinotti M. Congenital heart disease in the era of COVID-19 pandemic. Gen Thorac Cardiovasc Surg. 2021;69(1):172-4.

15. Schwerzmann M, Ruperti-Repilado FJ, Baumgartner H, Bouma B, Bouchardy J, Budts W, Campens L, Chessa M. Clinical outcome of COVID-19 in patients with adult congenital heart disease. Heart 2021:heartjnl-2020-318467.

16. Madjid M, Safavi-Naeini P, Solomon SD, Vardeny O. Potential effects of coronaviruses on the cardiovascular system: a review. JAMA Cardiol. 2020;5(7):831-40.

17. Figliozzi S, Masci PG, Ahmadi N, Tondi L, Koutli E, Aimo A, et al. Predictors of adverse prognosis in COVID-19: a systematic review and meta-analysis. Eur J Clin Invest. 2020;50(10):1-15.

18. Shi S, Qin M, Shen B, Cai Y, Liu T, Yang F, et al. Association of cardiac injury with mortality in hospitalized patients with COVID-19 in Wuhan. China JAMA Cardiol. 2020;5(7):802-10.

19. Brown AO, Millett ER, Quint JK, Orihuela CJ. Cardiotoxicity during invasive pneumococcal disease. Am J Respir Crit Care Med. 2015;191(7):739-45. 
20. Virzì GM, Clementi A, Brocca A, Ronco C. Endotoxin effects on cardiac and renal functions and cardiorenal syndromes. Blood Purif. 2017;44(4):314-26.

21. Zheng Z, Peng F, Xu B, Zhao J, Liu H, Peng J, Li Q, Jiang C, Zhou Y, Liu S, Ye C, Zhang P, Xing Y, Guo H, Tang W. Risk factors of critical \& mortal COVID-19 cases: a systematic literature review and meta-analysis. J Infect. 2020;81(2):e16-25.

22. Zheng YY, Ma YT, Zhang JY, Xie X. COVID-19 and the cardiovascular system. Nat Rev Cardiol. 2020;17(5):259-60.

23. Jirak P, Larbig R, Shomanova Z, Fröb EJ, Dankl D, Torgersen C, et al. Myocardial injury in severe COVID-19 is similar to pneumonias of other origin: results from a multicentre study. ESC Heart Fail. 2021;8(1):37-46.

24. Basso C, Leone O, Rizzo S, De Gaspari M, Van Der Wal AC, Aubry MC, et al. Pathological features of COVID-19-associated myocardial injury: a multicentre cardiovascular pathology study. Eur Heart J. 2020;41(39):3827-35.

25. Libby P, Lüscher T. COVID-19 is, in the end, an endothelial disease. Eur Heart J. 2020;41(32):3038-44.

26. Dabbagh MF, Aurora L, D'Souza P, Weinmann AJ, Bhargava P, Basir MB. Cardiac tamponade secondary to COVID-19. JACC Case Rep. 2020;2(9):1326-30.

27. Farina A, Uccello G, Spreafico M, Bassanelli G, Savonitto S. SARS-CoV-2 detection in the pericardial fluid of a patient with cardiac tamponade. Eur J Intern Med. 2020;76:100-1.

28. Khanduri A, Anand U, Doss M, Lovett L. Severe acute mitral valve regurgitation in a COVID-19-infected patient. BMJ Case Rep. 2021;14(1):e239782.

29. Wang D, Hu B, Hu C, Zhu F, Liu X, Zhang J, Wang B, Xiang $\mathrm{H}$, Cheng Z, Xiong Y, Zhao Y, Li Y, Wang X, Peng Z. Clinical characteristics of 138 hospitalized patients with 2019 novel coronavirus-infected pneumonia in Wuhan China. JAMA. 2020;323(11):1061-9.

30. Kochi AN, Tagliari AP, Forleo GB, Fassini GM, Tondo C. Cardiac and arrhythmic complications in patients with COVID-19. J Cardiovasc Electrophysiol. 2020;31(5):1003-8.

31. O'Shea CJ, Thomas G, Middeldorp ME, Harper C, Elliott AD, Ray N, Lau DH, Campbell K, Sanders P. Ventricular arrhythmia burden during the coronavirus disease 2019 (COVID-19) pandemic. Eur Heart J. 2021;42(5):520-8.

32. Dani M, Dirksen A, Taraborrelli P, Torocastro M, Panagopoulos D, Sutton R, et al. Autonomic dysfunction in "long COVID": rationale, physiology and management strategies. Clin Med. 2021;21(1):e63-7.

33. Goldstein DS. The extended autonomic system, dyshomeostasis, and COVID-19. Clin Auton Res. 2020;30(4):299-315.

34. Verdoni L, Mazza A, Gervasoni A, Martelli L, Ruggeri M, Ciuffreda M, Bonanomi E, D'Antiga L. An outbreak of severe Kawasaki-like disease at the Italian epicentre of the SARSCoV-2 epidemic: an observational cohort study. Lancet. 2020;395(10239):1771-8.

35. Jabri A, Kalra A, Kumar A, Alameh A, Adroja S, Bashir H, Nowacki AS, Shah R, Khubber S, Kanaa NA, Hedrick DP, Sleik KM, Mehta N, Chung MK, Khot UN, Kapadia SR, Puri R, Reed $\mathrm{GW}$. Incidence of stress cardiomyopathy during the coronavirus disease 2019 pandemic. JAMA Netw Open. 2020;3(7):e2014780.

36. Shah RM, Shah M, Shah S, Li A, Jauhar S. Takotsubo syndrome and COVID-19: associations and implications. Curr Probl Cardiol. 2021;46(3):100763.

37. The European Society for Cardiology. ESC guidance for the diagnosis and management of CV disease during the COVID-19 pandemic. https://www.escardio.org/Education/COVID-19-and-Cardi ology/ESC-COVID-19-Guidance. Accessed 20 May 2021

38. Roffi M, Capodanno D, Windecker S, Baumbach A, Dudek D. Impact of the COVID-19 pandemic on interventional cardiology practice: results of the EAPCI survey. EuroIntervention. 2020;16(3):247-50.

39. Moreno R, Díez JL, Diarte JA, Macaya F, Paredes E, et al. Consequences of canceling elective invasive cardiac procedures during Covid-19 outbreak. Catheter Cardiovasc Interv. 2021;97(5):927-37.

40. Nef HM, Elsässer A, Möllmann H, et al. Impact of the COVID-19 pandemic on cardiovascular mortality and catherization activity during the lockdown in central Germany: an observational study. Clin Res Cardiol. 2021;110(2):292-301.

41. Hollander JE, Carr BG. Virtually perfect? Telemedicine for Covid-19. N Engl J Med. 2020;382(18):1679-81.

42. Mantica G, Riccardi N, Terrone C, Gratarola A. Non-COVID-19 visits to emergency departments during the pandemic: the impact of fear. Public Health. 2020;183:40-1.

43. Garrafa E, Levaggi R, Miniaci R, Paolillo C. When fear backfires: Emergency department accesses during the Covid-19 pandemic. Health Policy. 2020;124(12):1333-9.

44. De Rosa S, Spaccarotella C, Basso C, et al. Reduction of hospitalizations for myocardial infarction in Italy in the COVID-19 era. Eur Heart J. 2020;41(22):2083-8.

45. Solomon MD, McNulty EJ, Rana JS, Leong TK, Lee C, Sung SH, Ambrosy AP, Sidney S, Go AS. The Covid-19 pandemic and the incidence of acute myocardial infarction. N Engl J Med. 2020;383(7):691-3.

46. Baldi E, Sechi GM, Mare C, Canevari F, Brancaglione A, Primi R, Klersy C, Palo A, Contri E, Ronchi V, Beretta G, Reali F, Parogni P, Facchin F, Bua D, Rizzi U, Bussi D, Ruggeri S, Oltrona Visconti L, Savastano S, Lombardia CARe Researchers. Out-ofhospital cardiac arrest during the Covid-19 outbreak in Italy. $\mathrm{N}$ Engl J Med. 2020;383(5):496-8.

47. Dudas K, Lappas G, Stewart S, Rosengren A. Trends in out-ofhospital deaths due to coronary heart disease in Sweden (1991 to 2006). Circulation. 2011;123(1):46-52.

48. Tam CF, Cheung KS, Lam S, et al. Impact of coronavirus disease 2019 (COVID-19) outbreak on ST-segment-elevation myocardial infarction care in Hong Kong, China. Circ Cardiovasc Qual Outcomes. 2020;13(4):e006631.

49. Primessnig U, Pieske BM, Sherif M. Increased mortality and worse cardiac outcome of acute myocardial infarction during the early COVID-19 pandemic. ESC Heart Fail. 2021;8(1):333-43.

50. Scholz KH, Maier SKG, Maier LS, et al. Impact of treatment delay on mortality in ST-segment elevation myocardial infarction patients presenting with and without haemodynamic instability: results from the German prospective, multicenter FITT-STEMI trial. Eur Heart J. 2018;39(13):1065-74.

51. Kitahara S, Fujino M, Honda S, Asaumi Y, Kataoka Y, Otsuka F, Nakanishi M, Tahara Y, Ogata S, Onozuka D, Nishimura K, Fujita T, Tsujita K, Ogawa H, Noguchi T. COVID-19 pandemic is associated with mechanical complications in patients with STelevation myocardial infarction. Open Heart. 2021;8(1):e001497.

52. Holt A, Gislason GH, Schou M, Zareini B, Biering-Sørensen T, Phelps M, Kragholm K, Andersson C, Fosbøl EL, Hansen ML, Gerds TA, Køber L, Torp-Pedersen C, Lamberts M. New-onset atrial fibrillation: incidence, characteristics, and related events following a national COVID-19 lockdown of 5.6 million people. Eur Heart J. 2020;41(32):3072-9.

53. Bollmann A, Hohenstein S, König S, Meier-Hellmann A, Kuhlen R, Hindricks G. In-hospital mortality in heart failure in Germany during the Covid-19 pandemic. ESC Heart Fail. 2020;7(6):4416-9.

54. Cox ZL, Lai P, Lindenfeld J. Decreases in acute heart failure hospitalizations during COVID-19. Eur J Heart Fail. 2020;22(6):1045-6. 